\title{
Economía Social y Solidaria como configuración heterogénea y diversa. El caso de la Provincia de Mendoza (Argentina)
}

\section{Emanuel Alberto Jurado}

RESUMEN: El desarrollo de la Economía Social y Solidaria (ESS) ha generado un marcado interés académico y político en Latinoamérica y, particularmente, en Argentina. Con origen en los últimos años del siglo pasado y los primeros del actual, en un contexto de crisis social y económica, este fenómeno puede entenderse como un conjunto heterogéneo de experiencias socio-económicas que contemplan elementos asociativos, autogestivos y democráticos, así como vínculos solidarios con su comunidad de pertenencia en general.

Por medio de una metodología cualitativa, el presente escrito se propone como objetivo la elaboración de una sociogénesis de estas prácticas en la Provincia de Mendoza (Argentina), buscando dar una respuesta al interrogante acerca de la existencia (o no) de una configuración de la ESS en ese espacio geográfico. Para ello se identifican y describen procesos acaecidos entre los últimos años de la década de 1990 y el año 2015, como así también sujetos que, de manera más o menos sostenida, han avanzado en mayores grados de organización. Se entiende que un proyecto de ESS, en tanto configuración, precisaría de la generación de articulaciones que trasciendan las unidades productivas individuales, es decir, que apunten a una coordinación política y económica más amplia.

Finalmente, se mencionan las principales cuestiones involucradas en este conjunto particular de experiencias concretas y se plantea un posible eje de trabajo a futuro para este mismo espacio geográfico. Asimismo, se propone que las herramientas analíticas empleadas en este trabajo específico puedan ser adaptables al estudio de otras realidades.

PALABRAS CLAVE: Economía Social y Solidaria, configuración, sociogénesis, trabajadores, productores, organizaciones sociales.

CLAVES ECONLIT: A13, B51, K00, P40, Z13.

Cómo citar este artículo/How to cite this article: JURADO, E.A. (2021): "Economía Social y Solidaria como configuración heterogénea y diversa. El caso de la Provincia de Mendoza (Argentina)", CIRIEC-España, Revista de Economía Pública, Social y Cooperativa, 102, 259-289. DOI: 10.7203/CIRIEC-E.102.16177.

Correspondencia: Emanuel Alberto Jurado, Grupo de Trabajo "Geografías Emergentes", Instituto de Geografía, Universidad de Buenos Aires (Argentina), emanuel.jurado@gmail.com, ORCID: 0000-0002-94914326. 


\section{Expanded abstract}

\section{Social and Solidarity Economy as an heterogeneous and diverse configuration. The case of the Province of Mendoza (Argentina)}

\section{Objectives Objectives Methodology}

The development of processes framed within the so-called Social and Solidarity Economy (SSE) has attracted considerable academic and political interest in Latin America, particularly in Argentina. Originating in the final years of the last century in a context of social and economic crisis, this phenomenon can be understood in empirical terms as a set of heterogeneous socio-economic experiences that have performed differently from the typical capitalist enterprise and with relative autonomy from state institutions as productive units that include associative, self-managed and democratic elements, as well as binds based on solidarity to other organisations in the field and their community in general (Pastore, 2010).

The general objective of this paper is to describe the development of the SSE in the Province of Mendoza (Argentina) over the last two decades, seeking to detect the existence (or not) of a "configuration of social relations" (De la Garza Toledo, 2011) linked to this field. It is assumed that the development of a conglomerate of SSE organizations in a specific spatio-temporal context depends on the different subjects involved in it, which are connected to each other through a set of disputes and agreements, giving unity and identity to this socio-economic group.

The analytical challenge of this work lies in recognising the accumulation of diverse experiences related to the SSE in Mendoza and identifying spaces of coordination between them that give them a certain unity as a whole. In other words, the aim is to transcend microscopic analyses that focus exclusively on the internal modes of work of a particular cooperative (Chaves, 1999) in order to concentrate on the processes and subjects of the SSE which, in a specific geographical environment, have made possible the emergence and constitution of new social subjects, different from those formed by capital (Rincón Gamba, 2011).

This research is part of a line of work that focuses its attention on broad and heterogeneous empirical trajectories, most of which exceed the established institutional framework. The reason for this position lies in the empirical condition of the sector in Argentina and, particularly, in Mendoza; formal registers in this geographical space present, in many cases, outdated data and are not sufficient to capture informal cooperative practices, which have emerged and gained relevance over the past two decades (Gudiño, 2015; Roitman, 2011). 


\section{Methodology}

The research approach is qualitative because its interest is directed at the ways in which the social world -the SSE in Mendoza- is interpreted, understood, experienced and produced (Vasilachis, 2006). Therefore, the data obtained through an inductive approach have been sensitive to the social context in which they have been produced.

In specific terms, the research work consisted, in the first place, of compiling and reading information from secondary sources: academic articles, journalistic writings, institutional diagnoses and legal norms. In addition, there was another invaluable secondary source of information: a set of emails from the organisations that make up this network, which contained minutes of meetings and newsletters from these organisations. This was complemented with anthropological work materialised through a prolonged presence at various events associated with the subject in Mendoza between 2010 and 2015, in order to carry out adequate direct observation, not only to bring into play the ability to "see", but also to "interact" with the "other" (Ameigeiras, 2006:113), all of which took the form of ethnographic work condensed into field notes. With this material, over the course of 2015, four in-depth interviews were carried out, defined by means of purposeful sampling (Quinn Paton, 2002), given that people were selected from whom relevant and valuable information was expected to be obtained (Stake, 1998) due to their trajectory linked to the SSE. Most of these tasks and the access to detailed information on the actions carried out in the framework of the SSE were achieved thanks to the immersion and participation of the researcher in the very processes that were analysed. It was an interactive work between the one who writes and the subjects, descriptive and analytical. Finally, the systematisation of all the material obtained was carried out between 2016 and 2018.

\section{Results}

After the analysis of the entire SSE trajectory in the Province of Mendoza from its origins in the late 1990s until 2015, the work has found a line of historical and political continuity with roots in the unemployed movements and barter networks on the one hand, and the Mesa de Economía Social Mendoza (MESM, Round Table of Social Economy) and the Foro de Economía Social Mendoza (FESM, Forum of Social Economy), on the other. In other words, the main result of this research is the identification and description of a "configuration of the SSE" in Mendoza.

This configuration began to take form from an initial stage of resistance and demands towards the state in a context of social emergency that encouraged many individuals to choose economic alternatives outside the catalogue of possibilities that were being considered at the time. For their part, both the MESM and the FESM were the political spaces that were specifically defined as instigators and promoters of the configuration of the SSE in Mendoza. In both cases, they were multi-sectoral networks.

Another central aspect, as a basic unifying factor for this configuration, was the realization, in 2012, of the 5th Regional Forum on Social Economy, which ocurred together with the 2nd National Forum "Towards Another Economy". These events changed the form of work consid- 
erably between the cooperatives, with the presence of various academics recognised in the field, as well as officials from the National Ministry of Social Development and other national and provincial agencies. A legal action was also carried out in the provincial legislature with the aim of the promotion of the sector. This meeting condensed the qualities of a revulsive "event" (Santos, 1996; Silveira, 2013) given that it transformed the fabric of the SSE, giving a certain unity and identity to the configuration of this political space.

Finally, the configuration of the SSE took shape with the approval of Law $N^{\circ} 8.435$, which condensed many of the concerns, needs and objectives that have been present in the FESM and MESM.

\section{Conclusions}

The SSE in Mendoza, as a configuration, presents porous limits. This is probably due, among other things, to the absence of major definitions of its work and its economic project, which stems from the high degree of social, political and economic heterogeneity and diversity that characterise the configuration. If this diversity gives it a plurality of voices, it also feeds organisational fragmentation. In other words, the intersectoriality and flexibility of this field, which have been highlighted by the subjects themselves as instigating qualities of organisation, have, over time, become obstacles that prevent some progress for the SSE in the province, as in the case of the effective implementation of Law No. 8.435, a difficulty that cooperativism has also encountered elsewhere in Latin America (Da Ros, 2007).

\section{Original Value and Limitations}

The plurality of the configuration of SSE in Mendoza makes it possible to consider a large number of informal experiences that are part of it, which, among other things, is expressed in the limitation that takes the form in a high degree of instability of the whole process. For this reason, the objective of understanding a process such as this requires an in-depth approach to "what really exists" (Mora and Hinkelammert, 2005), an issue resolved by means of an interpretative analysis using a qualitative methodology.

However, it is necessary to dimension the size of the SSE configuration in Mendoza, which will allow us to better understand the impact of its activity (Carrasco and Buendía-Martínez, 2013) and, from there, to dynamise decision-making of the configuration in general, as well as the adjustment of public policies for the sector, among other ways.

This paper constitutes a starting point in this pending task, while at the same time providing some analytical tools for research in other geographical spaces with similar characteristics, the main contribution of this research.

Keywords: Social and Solidarity Economy, configuration, sociogenesis, workers, producers, social organizations. 


\section{Introducción}

El desarrollo de procesos enmarcados en la denominada Economía Social y Solidaria (ESS) ha despertado un marcado interés académico y político en Latinoamérica y, particularmente, en Argentina. Con origen en los últimos años del siglo pasado y los primeros del actual en un contexto de crisis social y económica, este fenómeno puede entenderse en términos empíricos como un conjunto heterogéneo de experiencias socio-económicas que se ha desenvuelto de manera diferenciada a la típica empresa capitalista y con relativa autonomía respecto a instituciones estatales. Se trata de unidades productivas que contemplan elementos asociativos, autogestivos y democráticos, así como vínculos solidarios con otras organizaciones del campo y con su comunidad de pertenencia en general (Pastore, 2010:12).

El objetivo general de este escrito se dirige a dar cuenta del devenir de la ESS en la Provincia de Mendoza ${ }^{1}$ durante poco más de las últimas dos décadas, buscando detectar la existencia (o no) de una configuración en la temática. Se parte del supuesto que el desenvolvimiento de un conglomerado de organizaciones de la ESS en un determinado contexto espacio-temporal depende de los diferentes sujetos intervinientes en el mismo, que se vinculan en un juego de disputas y acuerdos, aportándole unidad e identidad a ese conjunto socio-económico.

De manera general, el presente trabajo se inserta en el vasto campo de los estudios que analizan, en cuanto conjunto, a las diversas experiencias económicas asociativas en un espacio y tiempo determinados. En este sentido, hallamos investigaciones como la realizada por Monzón Campos y Chaves Ávila (2012) donde, tomando como escala de análisis la Unión Europea (UE), se lleva a cabo un informe sobre las entidades enmarcadas la economía social, ponderando su magnitud y señalando localizaciones, actividades realizadas, dificultades y aportes al desarrollo económico de la región. Por su parte, también en el marco de la UE, Carrasco y Buendía Martínez (2013) buscan medir el tamaño del sector cooperativo a través de la teoría de crecimiento económico, pretendiendo así -según las autoras- superar los dominantes análisis microeconómicos de la literatura económica. A una escala nacional, trabajos como el de Da Ros (2007) y el de Alarcón Conde y Álvarez (2018) ofrecen una mirada procesual (dinámica) del fenómeno a la vez que buscan ponderarlo en términos económicos en Ecuador y Colombia respectivamente. En este último caso, se emplea un Análisis de Redes Sociales que, entre otras cuestiones, permite conocer el grado de cohesión de las redes intersectoriales de la configuración de la economía social en ese espacio. Para el caso venezolano, Bastidas-Delgado y Richer (2001) recalcan el rol del amplio movimiento cooperativo, en tanto tipo de experiencia más antigua e institucionalizada, como el principal elemento articulador de este conjunto de trayectorias socio-productivas. En todos estos casos, las entidades analizadas se hallan registradas formalmente en los diferentes organismos estatales, es decir, se trata de economía social de carácter institucional.

1. Mendoza es una provincia ubicada en el centro oeste de Argentina, cuya población es de 1.738.929 habitantes según el último censo nacional de 2010 (quinta provincia más poblada del país). 
Sin embargo, existen otros trabajos que, buscando también caracterizar el conjunto de experiencias económicas asociativas en un determinado espacio geográfico, hacen referencia a trayectorias empíricas enmarcadas en procesos políticos más amplios y que exceden la formalidad instituida. Por ejemplo, para el caso de Ecuador, Coraggio (2012) refiere a una "economía popular solidaria" que incluye una pluralidad de actores económicos legalmente constituidos, como así también prácticas informales (empresas privadas, empresas públicas, cooperativas, unidades domésticas, emprendimientos autónomos, entre otros). Asimismo, alude al impulso y reconocimiento otorgado a estas experiencias a través de su mención de la Constitución Nacional de 2008, aunque el fenómeno excede largamente esa estatalidad lo que torna dificultosa su ponderación como sector económico. Por su parte, Lamaitre (2009) en relación a Brasil, identifica una serie de actores que, agrupados en relación a prácticas similares, han forjado una identidad común y un reconocimiento mutuo en torno a la denominada "EcoSol". En términos generales, según la misma Lemaitre (2009), las prácticas de la ESS se identifican a partir de dos rasgos característicos: la autogestión y su conformación como movimiento social. Estas características, según un análisis cronológico, se han construido a lo largo de un proceso que, si bien reconoce parte de sus raíces en el histórico movimiento cooperativista, se cimientan en procesos sociales más cercanos en el tiempo como los movimientos eclesiales de base y los movimientos sociales campesinos, recuperando a su vez la dinámica de debate en foros, en particular la experiencia del Foro Social Mundial (Singer, 2014).

Esta investigación continúa con la línea del segundo grupo de trabajos, ya que posa su atención en trayectorias empíricas amplias y heterogéneas, gran parte de las cuales exceden la institucionalidad establecida. El motivo de esta postura radica en la condición empírica del sector en Argentina y, particularmente, en Mendoza; los registros formales en este espacio geográfico presentan, en muchos casos, datos desactualizados además de no atender, como es lógico, a las prácticas cooperativas informales, las cuales han surgido y tomado relevancia durante las dos últimas décadas (cuestión ya apuntada en trabajos previos como el de Gudiño (2015) y Roitman (2011) en relación a esta misma provincia). Por ello, aquí se realiza una sociogénesis de este campo socio-económico identificando sus principales sujetos y los sucesos o hitos históricos desde la década de 1990 hasta el año 2015, momento en el que el mismo tomó forma adquiriendo cierta unidad e identidad.

Además de esta introducción, el presente artículo expone, en su segundo apartado, las principales coordenadas conceptuales a partir de un contexto latinoamericano, mientras que en el tercero, desarrolla las herramientas metodológicas y analíticas utilizadas a lo largo de la investigación. En el cuarto epígrafe, se contextualiza el problema de investigación, y en el quinto y el sexto, se describe el núcleo del trabajo empírico. Finalmente, se mencionan algunas conclusiones de la investigación y se abre una nueva línea de trabajo a futuro. 


\section{Economía social y solidaria como concepto situado}

Al llevar a cabo un estudio en torno a la ESS, necesariamente se debe tener en cuenta la pluralidad de enfoques, proyectos políticos y prácticas concretas que este campo contiene, dimensiones que en la praxis misma van entrelazadas, haciendo difícil su separación. A su vez, la consideración de esos aspectos ineludiblemente está definida por la situación espacio-temporal del problema de investigación, en este caso, la ESS en Mendoza (Argentina) durante las últimas dos décadas aproximadamente.

Para elaborar una estructura conceptual en la temática, se realiza una primera distinción basada, a grandes rasgos, en aspectos históricos y geográficos. Por un lado, existe una "economía social histórica" nacida en Europa en pleno siglo XIX al calor de las problemáticas sociales desencadenadas por el desarrollo industrial de la época, que cuenta con los valiosos aportes de Owen y Fourier, entre otros. Estas referencias fueron inspiradoras del "sindicalismo, las cooperativas y las mutualidades y, más ampliamente, de la Economía Social" (Vuotto, 2009:104). En la actualidad, la "economía social" con tintes institucionales, como así también el "tercer sector anglosajón", representan la continuidad de esta corriente histórica (Sajardo y Chaves, 1997). Mayormente, esta línea jurídico-institucional centra su análisis en cooperativas, mutuales y asociaciones legalmente constituidas, vinculándolas al denominado tercer sector, es decir, un sector socio-económico complementario a la economía del capital y el Estado (Defourny y Develteres, 1999). En Latinoamérica, el enfoque histórico de la ES permanece vigente representado, entre otros, por Elgue (2007) quien caracteriza a las organizaciones de este movimiento por la finalidad de servir a sus asociados/as, la autonomía de gestión y por considerar en sus estatutos un proceso de decisión democrático.

Sin embargo, los enfoques contemporáneos conocidos bajo diferentes rótulos como "economía solidaria" (Laville, 2004; Lemaitre, 2009; Singer, 2014), "economía popular" (Bastidas-Delgado y Richer, 2001; Tiriba, 2004), "economía social" y "economía del trabajo" (Coraggio, 2011) y "economía de solidaridad" (Razeto, 1993) -solo por nombrar las principales corrientes en este sentido- permiten una mejor comprensión del fenómeno estudiado en el presente trabajo. Esta segunda oleada a nivel mundial, que aquí se ha definido llamarla "economía social y solidaria", se erige desde la década de 1970 como una alternativa posible a las políticas neoliberales.

En términos conceptuales, la "economía solidaria" de vertiente francesa (Caille, 2003; Laville, 2004) hace hincapié en una mirada sustantiva (plural) del hecho económico apoyándose en dimensiones de la antropología económica (Polanyi, 2001; Mauss, 2012) y criticando la visión formalista de la economía neoclásica, entre otras razones, por sus análisis hipotético-deductivos que fuerzan a encajar el hecho económico con la teoría. En cambio, sostiene que es necesario afirmarse sobre las prácticas mismas para informar su existencia y analizarlas (Laville, 2004), cuestión relevante a la hora de dar cuenta de numerosas experiencias concretas en Argentina que suelen escapar a los registros institucionales. 
Por su parte, desde América Latina, Coraggio (2011) emplea el término "economía social" para referirse a un enfoque económico que pretende superar el contrapunto entre mercado capitalista y Estado, destacando el anclaje de su propuesta en la sociedad y la cultura y proponiéndola como una economía de transición hacia "otra economía" o "economía del trabajo". Asimismo, divide al campo económico en tres esferas relacionadas desigualmente: economía capitalista (dominante), economía pública y "economía popular" (EP). Esta última está integrada por las unidades domésticas (UD) que, empleando su fondo de trabajo, desarrollan diversas actividades económicas, ya sea de manera dependiente como independiente del capital, para alcanzar su subsistencia (Coraggio, 2012). Sin embargo, tomado como conjunto, una parte importante de la EP carece de una propuesta política transformadora y de organicidad interna; más bien, continúa subordinada a la lógica del capital. En cambio, otra parte de la EP es atravesada por diversas asociaciones voluntarias que conforman redes de cooperación, formales e informales (Coraggio, 2011, p. 110). Este tipo de vínculos permitirían identificar un conjunto de sujetos organizados que conformarían la ESS en tanto campo y proceso conciente de "transición de la economía mixta capitalista a una economía mixta del trabajo" (Coraggio, 2011:136), una especie de utopía orientadora de la práctica.

De lo dicho en el párrafo anterior, se desprende que el sujeto que interesa para un análisis en clave de ESS es el colectivo (Coraggio, 2011:229) y con objetivos políticos, no sólo por dirigir sus fuerzas a la asociación interna sino también por buscar articulaciones mayores que trasciendan los límites de la organización, con otras entidades del sector y por fuera del mismo. En otras palabras:

Pensar en (este) sujeto supone proyectos y objetivos compartidos, una historia y un futuro consensuados, pero sobre todo la participación en acciones colectivas, en organizaciones o movimientos con recurrencia de posicionamientos en los escenarios coyunturales de la sociedad, generando así nuevos escenarios y sentidos para la política pública

(Coraggio, 2011:230)

En definitiva, por su amplitud conceptual, su capacidad para dar cuenta de sujetos colectivos dinámicos y heterogéneos, y su pertinencia espacio-temporal, la noción de ESS se ajusta al objeto de estudio de este trabajo. A continuación, nos adentramos en algunos instrumentos metodológicos que permiten el análisis de este conglomerado de experiencias heterogéneas en Mendoza. 


\section{Herramientas metodológicas para la caracterización de una configuración socio-económica}

El desafío analítico y metodológico de esta investigación reside en reconocer el cúmulo de experiencias diversas relacionadas a la ESS en Mendoza e identificar espacios de articulación entre las mismas que le otorguen cierta unidad en cuanto conjunto. Es decir, lo que se busca es trascender los análisis microscópicos que únicamente centran su atención en el funcionamiento interno de una determinada organización cooperativa (Chaves, 1999:122) para hacer foco en los procesos y los sujetos de la ESS que, en un entorno geográfico específico, han posibilitado el surgimiento y la constitución de nuevos sujetos sociales, distintos de los que construye el capital (Rincón Gamba, 2011).

Para ello, se emplean dos categorías que, de forma explícita e implícita, han guiado el proceso de investigación. Por un lado, se recurre al aporte metodológico del configuracionismo latinoamericano (De la Garza Toledo, 2001; 2011) y para el análisis de la ESS en Mendoza se emplea la noción de "configuración" de relaciones sociales, la cual se halla impregnada de significados (el significado como mediación entre estructura y acción), con componentes cognitivos, emotivos, morales y estéticos, con predominio no absoluto de uno sobre los demás (De la Garza Toledo, 2011). La configuración en tanto herramienta analítica, resulta una guía metodológica (y epistemológica) que invita a dar cuenta de las "relaciones entre estructuras, subjetividades e interacciones" (De la Garza Toledo, 2011:249). En otras palabras, esta triada posibilita la identificación de "los sujetos pertinentes, pero analizando-articulando sus acciones y subjetividades" (De la Garza Toledo, 2001:18).

Por otro lado, como complemento de la configuración, se toma desde el campo de la geografía la categoría de "evento(s)" (Santos, 1996; Silveira, 2013). Se trata de "unidades significativas del tiempo y, por esa razón, su duración no es regida por el reloj o el calendario sino por su significado social, su sentido y su capacidad de cambiar la trama de la historia" (Silveira, 2013:21). Es decir, los eventos "cambian las cosas, transforman los objetos, dándoles, allí donde están, nuevas características" (traducción propia) (Santos, 1996:116). Así, los eventos son "resultado de la acción y, por esa razón, no hay eventos sin actores" (Silveira, 2013:21) o, como se prefiere en este trabajo, sin sujetos colectivos. El complemento con la configuración se da entonces en tanto y en cuanto por medio de los eventos se pueden desanudar y comprender la interrelación entre estructuras, subjetividades e interacciones. En el caso de Mendoza, esos eventos se traducirían en encuentros, reuniones, mesas de trabajo activados por diversos sujetos de la ESS para avanzar en mayores grados de organización política.

Se trata de una investigación de tipo cualitativa dado que su interés se dirige a las formas en las que el mundo social -la ESS en Mendoza- es interpretado, comprendido, experimentado y producido (Vasilachis, 2006). Por ello, los datos obtenidos por medio de una actitud inducti- 
va, han sido sensibles al contexto social en el que han sido producidos y, fundamentalmente, "apuntan a la comprensión de la complejidad o totalidad y el detalle" (Vasilachis, 2006:25).

En términos específicos, la tarea investigativa ha consistido, en primer lugar, en la recopilación y lectura de información proveniente de fuentes secundarias, a saber: artículos académicos, escritos periodísticos, diagnósticos institucionales y normas jurídicas. Además, se contó con otra invalorable fuente secundaria de información: diversos correos electrónicos de espacios integrantes de este entramado, los cuales contenían minutas de reuniones y difusión de estas organizaciones. Esto se complementó con una labor antropológica materializada a través de una presencia prolongada en diversos eventos asociados a la temática en Mendoza entre 2010 y 2015, de modo tal de realizar una adecuada observación directa, no solo para poner en juego la capacidad de "ver", sino también de "interactuar" con el "otro" (Ameigeiras, 2006:113), todo lo cual se plasmó en un trabajo etnográfico condensado en notas de campo. Con este material, a lo largo de 2015, se realizaron cuatro entrevistas en profundidad definidas por medio de un muestreo intencionado (Quinn Paton, 2002), dado que se apuntó a determinadas personas de las que se esperaba obtener información relevante y valiosa (Stake, 1998) por su trayectoria vinculada a la ESS. La mayor parte de estas tareas y el acceso a información detallada de las acciones llevadas a cabo en el marco de la ESS se lograron gracias a la inmersión en los mismos procesos analizados, en donde se participó. Fue un trabajo interactivo entre quien escribe y los sujetos, descriptivo y analítico, "privilegiando las palabras de las personas y su comportamiento observable como datos primarios (aunque) el análisis de cómo las personas «ven» las cosas no puede ignorar la importancia de cómo «hacen» las cosas" (Vasilachis, 2006:26). Finalmente la sistematización de todo el material obtenido se realizó entre 2016 y 2018.

\section{Contexto de surgimiento de la Economía Social y Solidaria en Mendoza}

La irrupción en la escena pública de este tipo de procesos asociativos ha estado vinculada habitualmente a momentos de convulsión histórica, cuestión que parece tener asidero en el caso de Argentina y, específicamente, de Mendoza. En este sentido, la crisis socio-económica que se terminó de desatar en este país en 2001 puede ser tenida en cuenta como un detonante para la emergencia de la ESS. Dicha crisis fue el resultado de factores tanto externos como internos. En el plano internacional, la hegemonía neoliberal desde la década de 1970, otorgó un lugar de relevancia al capital financiero, el cual ejerció cierta capacidad disciplinaria sobre el movimiento obrero y la intervención reguladora del Estado más propios de una vía industrialista. Las privatizaciones de empresas estatales y la toma de deuda caracterizaron aquellas décadas, con graves efectos sociales en los diferentes países donde eso sucedió. En Argenti- 
na, los gobiernos anteriores a la crisis se encargaron de impulsar ese modelo económico de corte neoliberal que, paulatinamente, fue destruyendo el tejido social. Se echaron por tierra los regímenes de promoción industrial, se eliminaron las preferencias que beneficiaban a las manufacturas nacionales en las compras del Estado, además de la promoción de despidos, en el marco de la privatización de numerosas empresas estatales, abriendo ingentes mercados y sectores productivos a las empresas extranjeras (Coscione, 2008).

En el caso de Mendoza, la oleada desindustrializadora y tercerizadora de la economía se expresó en un formato de "reconversión industrial" que impuso la transformación de los sectores tradicionalmente más relevantes de su economía (vitivinícola y petrolero), con el objeto de volverlos "competitivos" (Collado, 2006:2; en Canafoglia, 2013:75). Otra de las ramas productivas que se vio afectada durante esas décadas fue la conservera, produciéndose una elevada concentración económica en las grandes empresas del sector (Canafoglia, 2013:76). Por su parte, en la actividad agropecuaria -de manera general- se desarrollaron procesos que implicaron el avance de relaciones de producción capitalistas, en detrimento de las unidades domésticas tradicionales (campesinos/as, contratistas, etc.), y la concentración de la propiedad territorial y de la producción (Cortese, 2016:27). En el plano laboral, todo este trayecto que desembocó en la crisis de 2001 tuvo su correlato, entre otras cuestiones, en un índice de desocupación que en el cuarto trimestre de 2003 alcanzó el 12,4\%. Vale la pena resaltar que ese elevado índice afectó mucho más a las mujeres donde ese valor ascendió a 16,4\% (en hombres fue de 9,6\%) (DEIE, 2018).

Ante este panorama general, diversos sectores sociales comenzaron a diseñar diferentes estrategias organizativas y de supervivencia; ejemplo de ello, tanto en Argentina como en Mendoza, fue el movimiento piquetero (bloqueo de vías de comunicación como forma de protesta), el gran número de asambleas populares que le sucedieron a dicha crisis, la recuperación de empresas por parte de sus trabajadores y trabajadoras, los clubes del trueque (Hintze, 2003; Svampa, 2006; Zibechi, 2006; Pérez, 2009; Cortese et al., 2008). Asimismo, insertos en este contexto, se desarrollaron variados y numerosos emprendimientos productivos y de distribución de productos, como así también cooperativas de consumo, donde sus miembros, por medio del trabajo, buscaron alcanzar su subsistencia ante la emergencia social de aquellos años. Sin embargo, muchos de estos grupos y personas no sólo procuraron a través de sus emprendimientos la reproducción simple de la vida, sino que plantearon algunos mecanismos de trabajo y producción, buscando distanciarse de la lógica hegemónica del capitalismo. A una gran parte de estas experiencias económicas se las encuadró dentro del amplio conjunto de la ESS.

Al margen de la mejoría en la actividad económica en general y, particularmente, en los niveles de ocupación durante la primera parte de la década del siglo XXI (CENDA, 2006), los conflictos en torno al cierre de empresas y su posterior recuperación por parte de sus trabajadores/as no cesaron. Sumado a esto, la tasa de subempleo registró un aumento en los años 2008 y 2009 superando el 10\%, en tanto que el empleo no registrado alcanzó el 36\% para este último año (Pastore, 2010:7), lo cual refleja continuidades en relación a las condiciones de precariedad laboral de los años anteriores. Por ello, la articulación de experiencias y procesos organizativos de la ESS no detuvo su avance; surgieron nuevos gremios, federaciones y confe- 
deraciones según el rubro de actividad o el tipo de organización. En Mendoza, por ejemplo, el proceso de recuperación de empresas registraba al año 2012, ocho unidades productivas bajo control de sus trabajadores y trabajadoras. Vale la pena destacar el año 2005 como aquel en el cual aconteció el mayor número de recuperaciones (tres empresas pertenecientes al rubro agroalimenticio) (Ortubia Díaz y Jurado, 2015). Asimismo, en la segunda mitad de la década de 2000, se comienza a desarrollar una etapa de aglutinamiento en torno a la ESS, encarnado primeramente en la Mesa de Economía Social de Mendoza (MESM) y la Red de Bancos Populares (integrada por entidades que otorgaban microcréditos para pequeños/as emprendedores/ as) y posteriormente en el Foro de Economía Social Mendoza (FESM). Este último espacio de articulación puso en debate la necesidad de diseñar una legislación específica para la temática, cuestión que desembocó en la sanción de la Ley $\mathrm{N}^{\circ} 8.435$ que reconoce a los sujetos de la ESS y promociona y fomenta sus actividades, entre otros aspectos ${ }^{2}$. Precisamente, estas últimas consideraciones justifican el interés por dar cuenta del desenvolvimiento de este campo en Mendoza.

\section{Sociogénesis como llave de ingreso a la configuración de la Economía Social y Solidaria en Mendoza}

Como se ha dicho hasta aquí, la identificación y estudio de un conglomerado de la ESS, en este caso particular de Mendoza, implica un gran desafío metodológico y analítico. Dado su permanente dinamismo, una de las dificultades epistemológicas de dicha labor consiste en cómo captar esa realidad en permanente transformación, "impulsada por factores estructurales y a la vez subjetivos, tanto en cuanto acción como en cuanto subjetividad" (de la Garza Toledo, 2001:110). Para lograr dar cuenta de esos aspectos dinámicos, la narración que sigue se vertebra en torno a un relato cronológico que profundiza en algunos de los efectos sociales y políticos de la crisis de 2001 en Mendoza ya mencionados y finaliza en el año 2015, cuando este conjunto de prácticas concretas parece afianzarse y delinearse de forma clara, aunque con algunos gestos de desgaste. Se trata de una selección de acontecimientos, ya que la intención principal se dirige a captar aquellos sucesos y agrupamientos políticos pertinentes a la misma, es decir, experiencias organizativas multisectoriales, abiertas, flexibles y con pretensiones de horizontalidad.

2. En Argentina se han sancionado sólo tres leyes provinciales en la temática; además de Mendoza, en Entre Ríos existe la Ley $N^{\circ} 10.151$ que crea el Régimen de Promoción y Fomento de la Economía Social, y en Río Negro la Ley $N^{\circ} 4.499$ que promueve el Régimen de Promoción de los Mercados Productivos Asociativos. 


\subsection{Movimientos de desocupados y clubes del trueque: respuestas frente a la crisis}

Resulta difícil determinar cuál fue el primer impulso de unidad y reconocimiento mutuo de experiencias en torno a la construcción de la llamada "otra economía" en Mendoza. Sin embargo, la crisis socio-económica, cuyos síntomas más evidentes y trágicos se condensaron en los sucesos de diciembre de 2001, puede ser reconocida como el detonante de diversos procesos tendientes a solucionar 0 , al menos, aliviar algunos de los problemas sociales más acuciantes por aquel entonces (desempleo, alimentación, salud, vivienda), para una parte importante de la población. Por ello, numerosas experiencias que se desarrollaron en el seno de diversos movimientos de desocupados/as y clubes de trueque, pueden ser consideradas como una fuente originaria de sentidos, ideas y prácticas encaminadas hacia una nueva economía social.

Por un lado, ante el ascenso ya señalado de los índices de desempleo durante los últimos años de la década de 1990 y los primeros de la década del 2000, el amplio movimiento de desocupados/as tomó forma y relevancia social. Así fue que la urgencia por la satisfacción de necesidades básicas empujó a diversas organizaciones de desocupados/as a realizar pedidos de bolsones de comidas a los supermercados, entre otras medidas (Lema, Bauzá y Gordillo, 2005). Frente a la gravedad de la situación, en 2002 el gobierno nacional implementó una fuerte política asistencial, buscando mitigar el aumento de la desocupación y la pobreza, por medio de los Planes Jefes y Jefas de Hogar Desocupados. Ante esto, los movimientos de desocupados/ as dirigieron sus demandas para obtener el mayor número posible de esos planes, mediante los cuales "se organizaron para realizar proyectos comunitarios y resolver urgencias como el hambre de los vecinos" (Lema et al., 2005).

Pasados los años de mayor urgencia económica donde lo que primaba era la resolución de las necesidades más elementales como la alimentación y la vestimenta, una parte importante de estos movimientos buscaron convertir aquellos subsidios en una herramienta de autoorganización y autogestión que permitiera el mejoramiento colectivo de las condiciones de vida en los barrios (Cortese et al., 2004). Uno de los ejemplos más concretos fue la iniciativa del Centro de Trabajadores Desocupados de Lunlunta (C.T.D.L.). Nacido en el año 2000 como consecuencia del cierre del tambo ${ }^{3}$ La Vacherie, en el Departamento Maipú (al sureste de la Ciudad de Mendoza), varias de las personas que quedaron desocupadas se agruparon en esta organización, ideando alternativas socio-económicas para afrontar la crisis de aquellos años. En un principio, empezaron con compras comunitarias y luego solicitaron planes sociales. Sabiendo de los límites de estas políticas sociales, comenzaron a gestionar emprendimientos productivos que les brindaran trabajo. Así, en un terreno prestado de tres hectáreas y media, iniciaron el cultivo de verduras de estación para el autoconsumo, especialmente tomates, que luego convirtieron en salsa, vendiendo el excedente a uniones vecinales, asambleas barriales y comedores comunitarios (Titiro, 2003). Uno de los integrantes del C.T.D.L señalaba en relación a su búsqueda con este tipo de actividades:

3. Establecimiento de ganado destinado al ordeñe, producción y venta, generalmente al por mayor, de leche cruda. 
(Queremos) hacer una economía solidaria, una economía alternativa, que nos permita precisamente a todos estos sectores excluidos del campo popular garantizar tal o cuál producto. Dirigir nuestra propia herramienta de producción... es un producto no deseado del sistema... demuestra que no es necesario que haya un patrón ni una organización vertical para poder desarrollar un emprendimiento...

(Lema et al., 2005)

Por su parte, otra respuesta que dieron varios sectores de la sociedad ante el aumento de los índices de desocupación y pobreza fue el trueque. Se trató de un proceso a nivel nacional que tuvo su correspondencia en la provincia de Mendoza y que posibilitó una forma de integración social, económica y cultural de miles de argentinos/as excluidos/as del mercado laboral y de otros espacios socio-económicos. Precisamente no sólo por su valor material, sino también por el desarrollo de otras potencialidades intangibles, es que se considera a este fenómeno como antecedente y parte de la ESS en Latinoamérica y, más específicamente, en Argentina y Mendoza. Según Abramovich y Vázquez (2003:3), lo destacable de este proceso social ha sido "el redescubrimiento de que la Moneda y los Mercados son construcciones sociales", contrario a lo que promueve el enfoque económico del mainstream que naturaliza ambos dispositivos. Ante la urgencia, lo que se colocó en juego fue el ejercicio del intercambio para satisfacer necesidades o, en términos más generales, la práctica económica como mecanismo para la reproducción de la vida, en lugar de estrategia para la acumulación de capital. De manera general, los elementos fundamentales del trueque han sido: los "prosumidores/as", es decir personas que ejercen su rol de consumidores/as y productores/as a la vez evitando la disociación que genera el capitalismo al alejar al productor del resultado de su labor; la "moneda social" que respalda la capacidad de producción y posibilita intercambios multirecíprocos dentro de una red; y los "nodos" y "redes" que posibilitan la ampliación y diversificación de la oferta y demanda de bienes y servicios, a través de una mayor extensión espacial del fenómeno (Abramovich y Vázquez, 2003:4).

En el caso de Mendoza, el primer nodo de trueque nació en 1997, convirtiéndose en uno de los eventos que posibilitaron el encuentro entre prosumidores/as y su interacción en el marco de una estructura socio-económica que condicionaba la reproducción simple de vastos sectores sociales. En poco más de un año, el número de nodos ${ }^{4}$ llegó a 20. Los principales nodos de la Red Global del Trueque (RGT) en esta provincia fueron: Meganodo en Luján de Cuyo (llegó a contar con 30.000 participantes en julio de 2002), Carlos Fourier en la Ciudad de Mendoza y San Cayetano en Guaymallén (Lacoste, 2003). Con importantes diferencias respecto de la RGT, en 1999 se crea la Fundación "El Prosumidor para Desarrollo Local Autosustentable" y de la mano de esta organización, comienza a circular el "EcoVale", la moneda local de los clubes de trueque integrantes de esta nueva red (Abramovich y Vázquez, 2003:25).

4. Los nodos fueron las unidades más pequeñas donde se llevaba a cabo el intercambio; basados generalmente en comunidades locales, a medida que el fenómeno fue creciendo, se convirtieron en los puntos de cruce y de encuentro de las redes de trueque. 
Sin embargo, con el paso del tiempo este proceso fue decayendo debido a diversas causas. Los principales factores endógenos que atentaron contra el sostenimiento de estas experiencias económicas fueron las divisiones internas o la aparición de monedas falsas. Ernesto, referente del trueque en Mendoza, agrega como dificultad, la imposibilidad de producir materias primas para lo que allí se elaboraba: "no se logró generar un modelo productivo en donde se incorporara la producción de insumos. Entonces no había insumos (y) apareció la escasez de productos" (entrevista, 26 de julio de 2015). La necesidad que hubo por acceder a insumos se generó, según el mismo referente, ante la falta de disponibilidad de efectivo para adquirirlos en el mercado tradicional. Finalmente, una vez que el peor momento de la crisis socioeconómica fue superado, algunas urgencias fueron aliviadas, por lo que estos procesos fueron perdiendo fuerza, desapareciendo en gran número ${ }^{5}$. Más allá de esta última consideración, aquellos eventos materializados en los clubes de trueque transformaron esa realidad, demostrando que el intercambio de bienes y servicios podía llevarse a cabo más allá de la moneda de curso legal.

Tanto los movimientos de desocupados/as como los clubes de trueques, acumularon experiencia organizativa y, en muchos casos autogestiva, para las trayectorias empíricas que, ante la imposibilidad de la plena inserción en el mercado laboral de los desocupados/as o de su inclusión de manera precaria (Pastore, 2010), se recrearon con posterioridad. En Mendoza, otros espacios de articulación política surgieron y tomaron notoriedad, siguiendo el camino trazado por aquellas trayectorias socioeconómicas.

\subsection{La heterogeneidad de la multisectorialidad}

Una parte importante de la experiencia acumulada en los movimientos de desocupados/as y los clubes del trueque, fue insumo vital para prácticas organizativas posteriores. Continuaron por su camino, en parte, el espacio de articulación política denominado "Organizaciones Sociales Autonconvocadas", "Multisectorial" y "Foro Social Mundial-Mendoza". Se hace referencia a una continuidad relativa dado que, por un lado, a diferencia del trueque y los movimientos de desocupados/as, fueron ámbitos políticos más flexibles donde la pertenencia a los mismos solía diluirse en participaciones puntuales por parte de las organizaciones que los componían. Este aspecto es de gran relevancia porque ha sido un elemento constante en la articulación política de la ESS en los procesos sociales que continuaron. Asimismo, la cuestión económica, aunque formaba parte de los temas abordados, no era el eje central en torno al cual giraban la mayoría de los debates. Sumado a esto, el foco hecho en el trabajo que caracterizaba obviamente a los movimientos de desocupados/as y, aunque en menor medida, a los/as participantes de los clubes del trueque, cedía frente a la gran heterogeneidad interna propia de estas organizaciones. Al margen de estas diferencias, se identifica en estas nuevas organizaciones pervivencia a la hora de promover la organización popular, fomentando ámbitos de debate e

5. Para el $4^{\circ}$ trimestre de 2006, la tasa de desempleo bajó en Argentina a 8,6\% (Ministerio de Trabajo, Empleo y Seguridad Social, s.f.) y en Mendoza a 3,6\% (DEIE, 2018). 
intercambio político, además de contar con la participación de referentes sociales comunes que dinamizaron sus actividades.

Una de estas organizaciones fue el espacio de articulación política conocido como Organizaciones Sociales Autonconvocadas, surgido en 2005. "Autoconvocados", como se la conocía en diversos ámbitos de militancia social, promovió un espacio de construcción social abierto a la participación de diversas organizaciones sociales que, por aquel entonces, existían en la provincia, vinculadas a la educación, la cultura, el trabajo, la niñez, la comunicación comunitaria, el medioambiente. Gran parte de sus integrantes provenían de experiencias político-partidarias de la década de 1970 en Mendoza, mientras que otros más jóvenes tenían sus orígenes en procesos de los años ' 80 y '90, nacidos al calor del neoliberalismo (Salomone, 2012:150). Entre las habituales organizaciones participantes de las reuniones se puede nombrar los ya mencionados C.T.D.L. y Fundación El Prosumidor, la Asociación Tierra de Niños, Profesionales de la Salud de la Asociación de Trabajadores del Estado (ATE), FEDEM, la Casa de la Expresión, la Cultura y el Arte (CECA), Club de Geografía (Facultad de Filosofía y Letras - UNCuyo), Foro Social Mundial-Mendoza, entre otros. Más allá de tratarse de una organización compleja y heterogénea, cierto reconocimiento mutuo se reflejó, con el tiempo, en un conjunto de preocupaciones comunes -protección del espacio público, movilizaciones y manifestaciones contra la suba de tarifas de servicios públicos, difusión de acciones políticas diversas, organización de ferias populares de bienes y servicios variados, entre otras- y en el desafío para superar la fragmentación de las diversas miradas y demandas presentes (Salomone, 2012:150).

Por su parte, Multisectorial en Lucha fue un espacio político integrado por organizaciones sociales, gremiales, estudiantiles y partidarias, que tomaba notoriedad pública en cada una de las marchas que organizaba por las calles del microcentro de la ciudad de Mendoza. En esas movilizaciones se reclamaba por la recomposición salarial de los/as trabajadores/as en un contexto nacional de inflación, contra el aumento de tarifas de los servicios públicos y el boleto de transporte colectivo, entre otras demandas.

Por último, se cierra esta enunciación de experiencias organizativas diversas con el denominado Foro Social de Mendoza. Nacido como reflejo, a escala provincial, de los Foros Sociales Mundiales, el primer foro se llevó a cabo en 2006, y en la invitación al mismo, se planteaba un temario que incluía, entre otros tópicos, Economía Social y Empresas Recuperadas. La heterogeneidad y diversidad de esta organización es un aspecto compartido con los espacios políticos antes mencionados, y de manera más amplia, como se muestra en los próximos párrafos, es también una característica común con la marcha general de la ESS en Argentina (Pastore, 2010:2).

\subsection{De la multisectorialidad a la especificidad: cuando la Economía Social y Solidaria toma cuerpo}

Como se pudo ver en las experiencias citadas anteriormente, la heterogeneidad y diversidad han sido aspectos destacados de esas organizaciones, siendo la multisectorialidad un aspecto 
central que se desprende del análisis de sus prácticas y de sus convocatorias. En algunas de ellas, la demanda por trabajo digno ha sido un aspecto relevante, mientras que en otras, las alternativas económicas a la lógica del capital han estado presentes de manera explícita en algunos de sus escritos y encarnadas en algunas de sus organizaciones integrantes. Sin embargo, ninguno de estos espacios políticos tuvo como objetivo primordial el fomento y el fortalecimiento de la ESS propiamente dicha.

Para encontrar experiencias concretas cuyo trabajo girara específicamente en torno a la producción, distribución y consumo y otras actividades que promovieran la construcción de relaciones económicas asociativas y solidarias con posterioridad a 2001, hay que remitirse a aquellas que integraron la Mesa de Economía Social Mendoza (MESM). Este espacio político fue el primero que promovió directamente el desarrollo de la ESS en Mendoza, aunque ello no implicó una pérdida de la diversidad antes mencionada. Se inició a partir de inquietudes vinculadas a aspectos socioeconómicos, gran parte de ellas surgidas del espacio de Organizaciones Sociales Autoconvocadas, según afirma Ernesto (entrevista, 26 de julio de 2015), quien también participó de la MESM. Como su antecesora, se trató de una experiencia concreta de coordinación amplia, que abarcó diversas organizaciones sociales, a la que se sumaron entidades empresarias y organismos estatales. Su actividad se inició a fines del año 2006 bajo el nombre de Mesa Promotora Intersectorial de Economía Social y Desarrollo Local (Antolín, 2006). Entre las entidades y organizaciones que participaron de las reuniones de la Mesa, se pueden mencionar: Fundación Solidaridad, Fundación El Prosumidor, Asociación Cayé Cheiná, UST, Asociación de Productores de La Palmera, Asociación de Productores del Norte, Asociación Emprender Mendoza (ASEM), El Arca (Productores + Consumidores), Asociación de Iglesias Bautistas, Organizaciones Autoconvocadas de Mendoza, VALOS (Empresarios por la Responsabilidad Social Empresaria), Cáritas Mendoza, Centro Regional de Investigaciones Científicas y Tecnológicas (CRICYT, actualmente CCT Mendoza), Instituto Nacional Tecnología Industrial (INTI), Instituto de Desarrollo Rural (IDR), Kolping, Dirección de Economía Social del Gobierno de Mendoza, Asociación Huellas y la Secretaría de Salud de la CTA (Mesa de Economía Social Mendoza [MESM], 2009). Es decir, no sólo se destacan organizaciones dedicadas específicamente a la producción y comercialización de bienes y servicios en el marco de la ESS, sino también entidades religiosas, sindicales, estatales, de ciencias y tecnología, empresariales.

Según un documento interno elaborado para una de las primeras reuniones de la MESM, la organización se define como "un espacio en el que participan diversos sectores interconectados por valores compartidos" (MESM, 2009). Si bien no se aclara de manera explícita cuáles son esos valores, se deduce de la lectura de ese escrito que se hace referencia al carácter democrático, representativo y abierto del espacio. En este mismo sentido, respecto del enfoque de la economía, se esgrime el fin social de la misma, en contraposición a objetivos lucrativos o de rentabilidad. Algunos ejes de debate que se propusieron en este espacio giraron en torno al trabajo como actividad humana destinada a satisfacer necesidades, lo cual se vio condensado en gran medida, en el fomento del mencionado sujeto prosumidor, concepto que tuvo mucha popularidad por aquel entonces, particularmente en ámbitos donde se promovían experiencias autogestivas. 
La MESM tomó nota también de la gran proliferación de emprendimientos productivos individuales. En este sentido, la atención estuvo dirigida a promover la articulación política de los/ as microemprendedores/as. En el documento se puede leer:

tenemos sobradas experiencias del fracaso de microemprendimientos aislados que sucumben ante un mercado altamente concentrado (...) pensamos que es necesario crear nuevas formas asociativas, que partan desde la producción conciente, la distribución, el consumo responsable y las nuevas herramientas de intercambio...

(MESM, 2009)

En este caso, el asociativismo puede tomarse como una estrategia política de administración y gestión que permitiría la pervivencia de este tipo de emprendimientos en el marco de una economía capitalista. Otro término que aparece en este comunicado es el de "gestión asociada" concebida por la MESM como "una nueva forma de participación entre el Estado, el Mercado y la Comunidad, desde el diseño, la gestión, el control y la evaluación de las políticas públicas", cerrando el enunciado con un llamamiento al debate entre todos los actores, explicitando los intereses de cada uno, aunque reconociendo la necesidad de construir "una sociedad que contemple el interés de todos" (MESM, 2009). En esta última consideración se hace presente el deseo por construir una plataforma multisectorial, es decir, una suerte de alianza entre los sectores público, privado y de la ESS. Precisamente esta marcada apuesta por la multisectorialidad muestra, en la práctica y durante este periodo, un mayor involucramiento del Estado, a través de organismos nacionales, provinciales y municipales. Si bien el Estado no estuvo ausente anteriormente ya que, como se vio, contuvo la emergencia social por medio de diversos planes sociales, a través de la MESM se integra al proceso, delineando la política general del sector "desde adentro" por medio de organismos y funcionarios/as que se vinculan a la temática.

Finalmente, se destaca de sus comunicados la meta de definir un plan maestro a través de una organización estratégica que posibilite "a todos los sectores sumar esfuerzos en forma concertada y dejar de realizar acciones individuales aisladas que dan bajos resultados a la hora de transformar la realidad" (MESM, 2009). Con este último punto, ante el diagnóstico elaborado por la misma MESM en referencia a la elevada mortandad de los emprendimientos productivos de aquella época, resalta nuevamente la necesidad de asociarse para superar el nivel microeconómico en la acción y construir un espacio de articulación en una escala superior que posibilite no sólo mayor visibilidad, sino también incrementar las posibilidades de sostenimiento a través de una gestión colectiva. Si bien la MESM llevó a cabo diferentes encuentros, aquella reunión de mediados de 2009 de la cual se desprendió el documento citado, se convirtió en otro de los eventos estructurantes de la configuración que tomaba forma, por la relevancia de los principios y los objetivos enunciados en torno a la ESS. 


\subsection{En la construcción de una legislación específica: foros regionales de Economía Social}

Es posible que una las expresiones más representativas de la ESS en Mendoza se vea configurada en el Foro de Economía Social de Mendoza (FESM) ${ }^{6}$. Como señala Antonio, referente del FESM y de la asociación El Arca, "más que una institución formal, (el Foro) tenía que ser como un espacio de encuentro, de debate, un espacio abierto, intersectorial" (entrevista, 1 de agosto de 2015). Es preciso aclarar que el Foro o FESM -en singular-consistió en un espacio político flexible que aglutinó diversos sujetos, continuando con la tesitura de las articulaciones políticas mencionadas como antecedentes; mientras que los foros -en plural- refieren a grandes encuentros puntuales organizados por el FESM en diferentes departamentos de la provincia, donde se encontraban, para debatir en mesas y talleres temáticos, las organizaciones integrantes del mismo, agregándose otras agrupaciones y numerosos microemprendedores que habitualmente no participaban de este espacio político. Estos últimos también se convirtieron en eventos que transformaron el devenir de la configuración que tomaba una forma más legible. Más allá de esto, el Foro y los foros son dos componentes del mismo proceso.

El Foro nace como fruto de diversas acciones y procesos organizativos llevados a cabo por organizaciones, muchas de las cuales ya venían trabajando en la MESM, aunque como afirma Antonio (entrevista, 1 de agosto de 2015), se agregaron algunas experiencias tales como las provenientes del campo de la Agricultura Familiar (AF) y las empresas recuperadas por sus trabajadores/as. Precisamente en relación a la AF, es importante destacar la presencia de los sujetos integrantes de ese sector durante gran parte de la construcción del FESM, como así también a la inversa. Ambos espacios políticos han compartido jornadas, dada la afinidad en las demandas políticas y en las estrategias de articulación, a través de encuentros y foros ${ }^{7}$.

Sumado al nexo con el sector de la AF, tanto Antonio como Diego -otro referente del FESM representando al Estado-, con diferentes intensidades, destacan la novedosa participación en el Foro de los/as beneficiarios/as de los créditos del Programa del Banquito Popular de la Buena Fe (BPBF). En este sentido, Diego afirma: "Para mí -no sé si el resto de los compañeros tienen la misma lectura-, pero para mí, el Foro nace muy relacionado con los banquitos. Yo ya estaba en el ministerio, pero nace muy relacionado con los banquitos" (entrevista, 3 de diciembre de 2015). Se trata de emprendedores/as que han recibido créditos del programa denominado BPBF, el cual nace como proyecto dentro de la Dirección Nacional de Desarrollo Comunitario del Ministerio de Desarrollo Social de la Nación en el año 2002 (Asociación Civil Formar,

6. Si bien tanto la MESM como el FESM utilizan en su denominación el término "economía social", se prefiere utilizar "economía social y solidaria" dada su amplitud para incluir a numerosas miradas y experiencias concretas que se han desarrollado en la provincia a lo largo de todos los años incluidos en el análisis realizado en este trabajo.

7. Como ejemplo de este trabajo conjunto, el 1 de diciembre de 2011 la Mesa Provincial de Desarrollo Rural y el Foro de Economía Social de Mendoza organizaron el "Encuentro de Comercialización de la Agricultura Familiar" con el objetivo de intercambiar experiencias concretas en el ámbito de la distribución de productos, identificar dificultades en esas tareas y fomentar el intercambio entre experiencias exitosas en la materia (Bonus, Viani, Vargas y Palero, 2011). 
s.f.). Este sistema de microcrédito, también conocido comúnmente como "banquitos", llegó a Mendoza en 2004. Los/as emprendedores/as reciben el financiamiento, de manera individual, para llevar a cabo diversas actividades, ya sean productivas como de comercialización, pero en la mayoría se destaca el objetivo de obtener dinero para satisfacer las necesidades más urgentes de la economía doméstica. Asimismo, cada beneficiario/a se compromete de palabra y en forma solidaria -se conforman grupos receptores de cinco integrantes en donde todas las personas responden por las demás en caso de incumplimiento- a devolver los créditos, no estableciéndose garantía real alguna, salvo la confianza mutua (Rofman, 2014:89). Si bien, a la hora de la participación, ha predominado el individualismo por parte de la mayor parte de los/ as emprendedores/as, desde el mismo ministerio se previeron "instancias de construcción colectiva y organización" (Ministerio de Desarrollo Social, 2012), condensadas en encuentros, ferias, festejos, talleres de formación, entre otras. En Mendoza, un espacio de coordinación y debate vinculado a este programa de microcrédito lo constituyó, en un primer momento, la Red de Bancos Populares, la cual, según uno de sus referentes, "puso (...) su acción en la necesidad de promover espacios de diálogo y encuentro para ir generando, junto con otros, la conciencia de una Construcción de una Política Pública de Economía Social, en la búsqueda de un Marco Legal que la promueva y le dé sustentabilidad (Ruiz, s.f.)".

Posteriormente, la Red de Bancos Populares se integró al FESM, aunque en las diversas intervenciones y memorias de este último espacio político, se registró indistintamente la participación de diversas Organizaciones Regionales de esta red, como Fundación Vida Joven y un sinfín de emprendedores/as de manera individual, más allá de que hayan sido parte o no de la mencionada red. Es decir, nuevamente aparece la flexibilidad (y laxitud) como característica destacada de este tipo de espacios multiactorales. Más allá de esto, en términos generales, la participación de los/as beneficiarios/as del "banquito" en el Foro (bajo sus diferentes pertenencias) puede tratarse de un intento por tomar parte de un espacio de coordinación política que trascienda los límites del propio emprendimiento. Esto implicaría un nivel de solidaridad mayor y una apuesta política por superar cierta fragmentación ya mencionada en relación a este tipo de unidades productivas. No resulta menor esta última consideración, dado que reflejaría un nivel de consciencia política en estos integrantes que los motivaría a avanzar en mayores grados de organización en el marco de este sector. A la vez, esta participación contribuye a permear el FESM de las características propias de los beneficiarios de este tipo de microcrédito, otorgándole mayor heterogeneidad aún.

En relación a las metas a alcanzar, el Foro se propone "la promoción de emprendedores, productores, cooperativas de trabajadores y consumidores de este tipo de economía, la capacitación de estos actores, la difusión de sus prácticas" (FESM, 2009). Tan es así que con su surgimiento, busca

consolidar el desarrollo de un importante sector de la sociedad Mendocina (sic) que se nuclea en esto que hemos denominado El Foro Provincial de la Economía Social, (y con la clara) misión de construir una política provincial de Economía Social materializada en el armado de un Plan Estratégico para los próximos 10 años (2010-2020)

(Foro de Economía Social Mendoza [FESM], 2009) 
En el marco de dicho plan, este espacio político se propuso "encarar la revisión y construcción de una legislación integrada (...), que reconozca, proteja e impulse a los sujetos, actores sociales y gubernamentales de la Economía Social en Mendoza" (FESM, 2009).

Un aspecto que comienza a tornarse necesario para varios/as participantes es el imperativo por diseñar estrategias de comercialización para los/as productores/as de la ESS, ya que se perciben las dificultades que aparecen en la circulación de sus productos (notas de campo, 9 de septiembre de 2009). Precisamente reafirmando esto, Antonio recuerda de las primeras reuniones del Foro: "nos pusimos dos objetivos; uno de esos era que hubiera un marco legal y surgió eso con bastante fuerza, y el otro era generar centros de producción y consumo en la provincia" (entrevista, 1 de agosto de 2015).

Los foros han sido regionales, adhiriendo, según sus organizadores, al enfoque del Desarrollo Local (FESM, 2009), para lo cual ha sido indispensable involucrar y articular con los estados municipales. Por ello, se llevaron a cabo los siguientes foros: 1ํ Foro Regional de Economía Social "San Carlos", el 11 de septiembre de 2010; 2ํForo Regional de Economía Social "Las Heras", el 6 de noviembre de 2010; 3ํㅜㅇoro Regional de Economía Social "Maipú", el 9 de abril de 2011; 4ํ- Foro Regional de Economía Social “San Martín”, el 10 de septiembre de 2011; 5o Foro Regional de Economía Social en la Ciudad de Mendoza, el 10, 11 y 12 de mayo de 2012; 6응 Foro Regional de Economía Social "San Rafael”, el 8 de junio de 2013; y el $7^{\circ}$ Foro Regional de Economía Social “Guaymallén”, el 12 de junio de 2015.

En cuanto a la dinámica de trabajo, fue similar en casi todos los foros (presentaciones de las autoridades del municipio organizador, talleres, paneles, ferias de productores/as y conclusiones finales), como así también hubo coincidencias en los ejes sobre los que se discutió (formalización y seguridad social de trabajadores/as-productores/as, promotores/as y organizaciones de la ESS; centros de producción/comercialización por oasis productivos; marcas de productos de la ESS; uso productivo de tierras ociosas; compras del Estado; campañas de difusión de la ESS; inclusión de la ESS en la currícula de la educación formal; creación de organismo político, institucional, participativo, continuo, intersectorial con marco legal de ESS; entre otros tópicos) (notas de campo, 6 de noviembre de 2010).

El encuentro de mayor envergadura y cuya fuerza simbólica implicó un quiebre en este derrotero fue el $5^{\circ}$ Foro Regional, el cual fue ensamblado con el $2^{\circ}$ Foro Nacional "Hacia Otra Economía". En él mutó considerablemente la forma de trabajo, al contar con la presencia de diversos/as académicos/as reconocidos/as en la temática, además de funcionarios/as del Ministerio de Desarrollo Social de la Nación y otras dependencias nacionales y provinciales. Asimismo, se llevó a cabo un gran número de talleres, feria de productores/as de la ESS, una acción en la legislatura provincial con el objetivo de impulsar el anteproyecto de ley destinado a la promoción del sector (notas de campo, 10 de mayo de 2012). Si todos los foros son considerados eventos, particularmente este condensa las cualidades de un evento revulsivo dado que transformó la trama de la ESS, dándole cierta unidad e identidad a la configuración.

En resumen, según un documento interno del mismo Foro (FESM, 2013) de todo este proceso han participado, entre otros, los siguientes sujetos: 
- organizaciones sociales como la Red de Bancos Populares de Cuyo; Mesa de Empresas Recuperadas y Autogestionadas de Mendoza; Federación de Organizaciones de la Agricultura Familiar; Mesa de Economía Social; Instituto Movilizador de Fondos Cooperativos; Red de Comercio Justo Mendoza (integrada por la Unión de Trabajadores Rurales sin Tierra y El Almacén Andante, entre otras organizaciones); Red de Organizaciones Sociales de Las Heras; Red de Organizaciones Sociales de Maipú; "El Arca productores más consumidores"; entre otras;

- entidades municipales como la Municipalidad de San Carlos, Tunuyán, San Rafael, General Alvear y Malargüe; Dirección de Desarrollo Económico y Área de Economía Social de la Municipalidad de Las Heras; Área de Economía Social Municipalidad de Guaymallén; Dirección de Desarrollo Socio Económico de la Municipalidad de Maipú; Coordinación de Economía Social de la Municipalidad de San Martín;

- entidad provincial como la Dirección de Economía Social y Asociatividad (Ministerio de Desarrollo Social y Derechos Humanos); Subsecretaría de Agricultura, Ganadería y Alimentos (Ministerio de Agroindustria y Tecnología);

- entidades nacionales con sede en Mendoza como el Área de Economía Social del Centro de Referencia Mendoza (Ministerio de Desarrollo Social); CONAMI (Comisión Nacional de Promoción del Microcrédito); Registro Nacional de Efectores de la Economía Social; Subsecretaria de Agricultura Familiar (Ministerio de Agricultura, Ganadería y Pesca)

- entidades académicas como el Instituto del Trabajo y la Producción, Centro de Estudios de Economía Social (Facultad de Ciencias Políticas y Sociales) y la Secretaria de Extensión Universitaria de la Universidad Nacional de Cuyo; Instituto de Educación Superior "Rosario Vera Peñaloza" e Instituto de Educación Superior "Gral. José de San Martín".

La diversidad y pluralidad se refleja en la presencia de organizaciones sociales de base y espacios de coordinación política, asociaciones, cooperativas, empresas recuperadas, redes de microemprendedores/as (e, inclusive, microemprendedores/as individuales). Además, la participación de diferentes dependencias estatales demuestra el apoyo y el fomento técnico (con éxito dispar) a la configuración que para ese entonces, ya estaba afirmada.

En relación a los rubros productivos, los mismos han sido variados, aunque la mayor parte podría encuadrarse dentro del ámbito de los alimentos de base agropecuaria: frutas y verduras frescas, conservas y encurtidos (dulces, mermeladas, salsas, verduras y frutas envasadas), hierbas aromáticas, frutas y verduras deshidratadas, carnes y embutidos. Esto responde, en parte, al perfil productivo de la provincia. No obstante, también han sido partícipes del proceso fábricas recuperadas por sus trabajadores/as dedicas al trabajo en cuero, a la fabricación de cerámicos, a la gráfica e inclusive, al turismo.

Por otro lado, con la mencionada incorporación de un sinnúmero de microemprendedores/ as al FESM, la diversidad se torna aun mayor, dando lugar a productos artesanales de todo tipo (dulces caseros; panificados; trabajos en papel, madera, cartón, tela; sólo por nombrar algunos). Sin embargo, se puede decir que el mayor porcentaje de deserción del espacio lo encarnan estas trayectorias empíricas, dada la fragilidad económica, social y política de las mismas. 
La heterogeneidad también se refleja, en términos más generales, en los diferentes eslabones en el circuito productivo que son abarcados por estas experiencias concretas; lógicamente ha primado la presencia de unidades productivas, aunque también han participado comercializadoras como El Almacén Andante, El Arca (doble rol de organización productora y distribuidora de productos) y algunas organizaciones dedicadas a la coordinación de ferias. Igualmente, la diversidad está dada en el origen de los sujetos participantes de estos espacios, ya que no sólo se trata de trayectorias empíricas provenientes del medio urbano, sino también del ámbito rural. Justamente, el perfil de algunas de las instituciones estatales que han participado de este proceso y el fuerte vínculo con el sector de la AF, demuestran que la producción campesina ha sido esencial a la hora de conformar y articular un sector de ESS. Por todo esto, el Foro, al igual que la MESM, es definido como un espacio mixto, integrado por el Estado (y sus diversos organismos dedicados a la temática) y Organizaciones Sociales (FESM, 2009).

\section{La ley: ¿final del camino o continuidad de un proceso?}

Luego de este recorrido histórico, resulta lógico preguntarse si la sanción de la Ley N ${ }^{\circ} 8.435$ que establece un Programa de Promoción de la Economía Social y Solidaria cierra una etapa (0 varias etapas) para abrir otra en la configuración de la ESS en Mendoza. En mayo de 2012 se sancionó la mencionada ley, conteniendo gran parte de las inquietudes, necesidades y objetivos que han estado en el FESM y en la MESM. El 3 de diciembre de 2013 se reglamentó la Ley $\mathrm{N}^{\circ} 8.435$, reafirmando los principales conceptos y enunciados de la legislación sancionada y estableciendo las herramientas para su aplicación. Para la ley, se considera parte de la ESS al:

conjunto de recursos y actividades, y grupos, instituciones y organizaciones, que operan según principios de solidaridad, cooperación y autoridad legítima, en la incorporación y disposición de recursos para la realización de actividades de producción, distribución, circulación, financiamiento y consumo digno y responsable; cuyo sentido no es el lucro sin límites sino la resolución de las necesidades de los trabajadores, sus familias y comunidades, y del medio ambiente; para lograr una sociedad más justa, inclusiva e igualitaria

(Ley $\mathrm{N}^{\circ} 8.435$, art. 2, 2012)

Además de adoptar una definición, la ley describe a los sujetos de la ESS como aquellos que "poseen una gestión democrática y participativa, una organización económicamente equitativa, con justa distribución de los recursos, ingresos y beneficios” (Ley No 8.435, art. 3, 2012). Sumado a estos conceptos, se determina la creación de un Fondo Especial de Promoción de la ESS de \$ 5.000.000 ajustables, autorizando las correspondientes partidas presupuestarias para garantizar su ejecución a partir del año 2013; se designa al Ministerio de Desarrollo Social de la Provincia de Mendoza (a través de la Dirección de Economía Social y Asociatividad) 
como autoridad de aplicación de la misma; se crea el Consejo Provincial de Economía Social y Solidaria que deberá estar integrado por tres miembros representantes de organizaciones de la ESS, un miembro del sector académico y tres funcionarios/as ministeriales y que se encargará, entre otras cuestiones, de impulsar una Planificación participativa y estratégica junto con los diversos actores de la ESS (Ley $\mathrm{N}^{\circ} 8.435$, art. 6, 2012).

Sin embargo, los años que siguieron a la reglamentación de la ley no han mostrado grandes avances en su implementación, principalmente debido a la ausencia del presupuesto destinado a tal fin. Como afirma Hugo, uno de los principales referentes del Foro proveniente de la Universidad Nacional de Cuyo, a la ley "no la han dotado de recursos, y una ley sin recursos es una política que no se puede aplicar" (entrevista, 1 de agosto de 2015). Por otro lado, si bien el Consejo Provincial de Economía Social y Solidaria se presentó en marzo de 2014 en la empresa recuperada Gráficos Asociados (imprenta), luego de ello su funcionamiento no ha respondido a las expectativas de los/as mismos/as integrantes del Foro.

Una de las posibles causas de la desaceleración política del FESM puede hallarse justamente en la institucionalización del proceso que ha propiciado la sanción de la ley. Vale la pena señalar que la implementación debía estar a cargo de un consejo integrado por representantes, tanto de las organizaciones que integran el Foro como del Estado provincial (Ley $\mathrm{N}^{\circ} 8.435$, Art. 6, 2012). El peligro que encerraba esa posible institucionalización de una parte o de todo este proceso ya quedaba reflejada de manera previa a la sanción de dicha ley en las palabras de uno de los referentes del Foro y luego funcionario público en la temática:

El desafío es convivir con otros organismos que se puedan crear (con la sanción de la ley). El eje es el Foro de la economía social. Sin foro, por ahí sacan o cambian la ley y se fue todo. La transformación que buscamos entre todos tiene como base la comunidad organizada. Esto tiene que existir siempre y ser el fogonero que proponga e interpele cualquier política pública de economía social

(Ruiz, 2011)

Sin embargo, la práctica concreta ha expresado, hasta el año 2015, muy poca actividad del Consejo. Es decir, los hechos apuntan a sostener que la institucionalización del proceso ha atentado contra su propio dinamismo.

Más allá de estos problemas, todo este proceso, como se dijo, ha permitido instalar en el debate social -en general- y en el entramado institucional -en particular-, la posibilidad de llevar a cabo prácticas enmarcadas bajo otros principios. Si en los primeros foros abundaba el desconocimiento general del sector, con el paso del tiempo, como afirma Diego, "empezamos a ser reconocidos o identificados o nos descubrieron en ámbitos que no sabían que existíamos, hasta dentro del mismo Estado provincial..." (entrevista, 3 de diciembre de 2015).

Así, la configuración tomó forma en el entramado de las subjetividades (sujetos) colectivas y sus interacciones que fueron transformando su esencia. Todo ello se dio en el marco de una crisis socio-económica y la posterior reactivación económica que definió una estructura socio-económica condicionante en un principio y que luego posibilitó el despegue de la ESS, a medida que el sector cobró visibilidad pública. 


\section{Consideraciones finales}

Luego de todo el derrotero de la ESS en la Provincia de Mendoza descripto desde sus orígenes a fines de las década de 1990 -en el marco de una gran crisis socio-económica en Argentinahasta 2015 -año en el que el proceso comenzó a mostrar algunos signos de agotamiento según sus mismos sujetos-, se puede afirmar que en Mendoza existe una configuración socio-económica en la temática.

De manera general, se constata una línea de continuidad histórica y política con extremos temporales en los movimientos de desocupados/as y los clubes de trueque por un lado, y la MESM y el FESM, por el otro. Así, se observa una primera etapa de resistencia y demanda al Estado en un contexto de emergencia social que animó a numerosos sujetos a optar por alternativas económicas fuera del catálogo de posibilidades que se barajaba por ese entonces. Por su parte, tanto la MESM como el FESM fueron los espacios políticos que se definieron específicamente como instigadores y promotores de la "configuración de la ESS" en Mendoza. Se trató, en ambos casos, de articulaciones multisectoriales, aunque en el primero, además de las organizaciones y el Estado, hubo presencia del sector empresarial, cuestión que casi desapareció en el segundo.

Más allá de esta diferencia, ambas instancias organizativas posibilitaron el encuentro de experiencias concretas en ESS y el establecimiento de redes comerciales que favoreció el "reconocimiento mutuo" (Lemaitre, 2009) en tanto participantes de algo común que, a grandes rasgos, los mismos sujetos entienden como asociativismo y cooperativismo. Otro aspecto central, en tanto aglutinante básico para esta configuración, ha sido la condición de trabajador/a, vinculada a su vez con la condición de productor/a que se ha propuesto, de diversas maneras, en los eventos relacionados a la ESS, lo que permeó las subjetividades que allí han transitado.

Ahora bien, en tanto configuración, sus límites no son claros, sino más bien porosos (¿acaso existe alguna configuración de este tipo que se pueda demarcar claramente?). Probablemente esto se deba, entre otras cuestiones, a la ausencia de grandes definiciones respecto de su labor y de su proyecto económico originadas en la elevada heterogeneidad y diversidad social, política y económica, aspectos que caracterizan a la configuración. Si esa diversidad le otorga pluralidad de voces, también alimenta una fragmentación organizacional. En otras palabras, la intersectorialidad y flexibilidad de este campo, que han sido destacadas por los mismos sujetos como cualidades instigadoras de la organización, se han tornado con el paso del tiempo en obstáculos que no permiten algunos avances para la ESS en la provincia, como el caso de la efectiva implementación de la Ley $\mathrm{N}^{\circ} 8.435$, dificultad con la que se ha encontrado el cooperativismo también en otros espacios de América Latina (Da Ros, 2007).

Finalmente, la pluralidad de esta configuración permite considerar como integrantes de la misma a un gran número de experiencias concretas informales, lo cual, entre otras cuestiones, se expresa en un elevado grado de inestabilidad de todo el proceso. Por ello, el objetivo de conocer un proceso como este requiere de un acercamiento profundo a "lo realmente existente" (Mora y Hinkelammert, 2005), cuestión resuelta mediante un análisis de carácter interpretativo por medio de una metodología cualitativa. Sin embargo, es menester reconocer el valor y la 
necesidad de dimensionar el tamaño de la configuración de la ESS en Mendoza, lo que permitirá conocer el impacto de su actividad (Carrasco y Buendía-Martínez, 2013) y, a partir de allí, dinamizar la toma de decisiones de la configuración en general, como así también el ajuste de las políticas públicas para el sector, entre otros caminos. El presente escrito se constituye en un punto de partida en esa tarea pendiente, a la vez que otorga algunas herramientas analíticas para investigaciones en otros espacios geográficos de similares características.

\section{Bibliografía}

ABRAMOVICH, A.L. \& VÁZQUEZ, G. (2003): "La experiencia del trueque en la Argentina: otro mercado es posible", Seminario de Economía Social, Instituto de Estudios y formación de la CTA, julio.

ALARCÓN CONDE, M.Á. \& ÁLVAREZ, J.F. (2018): “La dimensión sectorial del cooperativismo colombiano a través de un análisis de redes", CIRIEC-España, Revista de Economía Pública, Social y Cooperativa, 92, 121-154. DOI: 10.7203/CIRIEC-E.92.10606

AMEIGEIRAS, A. (2013): “El abordaje etnográfico en la investigación social”. En: Vasilachis, I. (Coord.). Estrategias de investigación cualitativa. Barcelona: Gedisa Editorial, 107-152.

BASTIDAS-DELGADO, 0. \& RICHER, M. (2001): “Economía social y economía solidaria: Intento de definición", Cayapa-Revista Venezolana de Economía Social, 1 (1), noviembre. Disponible en: https://www.redalyc.org/pdf/622/62210102.pdf

BONUS, M., VIANI, M., VARGAS, M.F. \& PALERO, L. (2011): Investigación Fortalezas y debilidades en las estrategias de intercambio y comercialización de la agricultura familiar en la provincia de Mendoza. Informe Final. Consejo Federal de Inversiones. Mendoza. Disponible en: http://biblioteca.cfi.org.ar/wp-content/uploads/sites/2/2011/01/49143.pdf.

CAILLE, A. (2003): "Sobre los Conceptos de Economía en general y de Economía Solidaria”. En: Coraggio, José Luis. (org.). (2009). ¿Qué es lo económico? Materiales para un debate necesario contra el fatalismo. Buenos Aires: Ediciones CICCUS, 13-46.

CANAFOGLIA, E. (2013): La Argentina entre el 'modelo de valorización financiera' y el 'modelo de dólar alto': el desenvolvimiento de las pymes industriales, estrategias de reproducción y trabajo con referencia a la provincia de Mendoza. Un análisis desde la sociología económica. Tesis de doctorado. Facultad de Ciencias Políticas, UNCuyo, Mendoza, Argentina.

CARRASCO, I. \& BUENDÍA-MARTÍNEZ, I. (2013): “El tamaño del sector cooperativo en la Unión Europea: una explicación desde la teoría del crecimiento económico", CIRIEC-España, Revista de Economía Pública, Social y Cooperativa, № 78, pp. 125-148. Disponible en: https://www.redalyc.org/articulo.oa?id=17429865008. 
CENDA (2006): "El nuevo patrón de crecimiento y su impacto en el empleo", Notas de la Economía Argentina, 2, septiembre. Disponible en:

http://publicacioneseconomia.flacso.org.ar/images/pdf/1.24.pdf

CHAVES, R. (1999): "La Economía Social como enfoque metodológico, como objeto de estudio y como disciplina científica", CIRIEC-España, Revista de Economía Pública, Social y Cooperativa, 33, 115-140. Disponible en: https://roderic.uv.es/handle/10550/39640

CORAGGIO, J.L. (2011): Economía social y solidaria. El trabajo antes que el capital. Quito: Abya Yala.

CORTESE, C. (2016): "Documento: Notas introductorias para una aproximación al estudio de Mendoza como formación económico-social concreta" [Apuntes de clase], Cátedra Mendoza: Territorio, Población, Estructura Económica y Conflicto Social. Facultad de Ciencias Políticas y Sociales, UNCuyo, Mendoza.

CORTESE, C. et al. (2008): "Luchas y movimientos sociales en Mendoza 1993/2005. Respuestas a la desocupación, pobreza y crisis", Revista Confluencia, 7 (4), FCPyS, UNCuyo.

CORTESE, C., CORTESE, L., FERNÁNDEZ, D. \& PÉREZ, M. (2004): "Política social y política económica: La articulación necesaria para incidir en los niveles de pobreza", II Congreso Nacional de Políticas Sociales. Facultad de Ciencias Políticas y Sociales, Universidad Nacional de Cuyo, Mendoza, septiembre.

COSCIONE, M. (2008): "Tejer el Futuro: Campesinos, fábricas recuperadas y comercio justo", Revista Geográfica Digital, 10 (6), julio-diciembre. Instituto de Geografía, Facultad de Humanidades. UNNE. DOI: 10.30972/geo.5102829

DA ROS, G. (2007): “El movimiento cooperativo en el Ecuador. Visión histórica, situación actual y perspectivas", CIRIEC-España, Revista de Economía Pública, Social y Cooperativa 57, 249-284. Disponible en: https://www.redalyc.org/pdf/174/17405710.pdf

DEFOURNY, J. \& DEVELTERE, P. (1999): “Orígenes y perfiles de la Economía Social en el Norte y en el Sur". En: Defourny, Jacques, Develtere, Patrick y Fonteneau, Bénédicte (Comps.). La Economía Social en el Norte y en el Sur, Buenos Aires: Ediciones Corregidor, 33-84.

DE LA GARZA TOLEDO, E. (2001): "La epistemología crítica y el concepto de configuración", Revista Mexicana de Sociología, 1 (63). Disponible en:

http://sgpwe.izt.uam.mx/pages/egt/publicaciones/articulos/configuraciones.pdf

DE LA GARZA TOLEDO, E. (2011): "La metodología marxista y el configuracionismo latinoamericano". En: De la Garza Toledo, Enrique y Leyva, Gustavo (Eds.). Tratado de metodología de las ciencias sociales: perspectivas actuales, México: FCE/UAM, 229-255. 
ELGUE, M. (2006): La economía social. Por un empresariado nacional y democrático. Buenos Aires: Capital Intelectual.

GUDIÑO, M.E. (Dir) (2015): Territorio y Economía Plural: una aproximación al desarrollo. Mendoza: Universidad Nacional de Cuyo-Consejo Nacional de Investigaciones Científicas y Técnicas.

HINTZE, S. (Ed.) (2003): Trueque y Economía Solidaria. Buenos Aires: Universidad Nacional de General Sarmiento/Prometeo Libros.

JURAD0, E. (2018): Aspectos socio-espaciales de experiencias económicas alternativas: la economía social y solidaria en Mendoza de 2001 a 2017: un estudio desde los casos de El Arca y la Unión de Trabajadores Rurales sin Tierra. Tesis de doctorado. Universidad Nacional de Quilmes, Argentina.

LACOSTE, P. (2003): “La crisis socioeconómica argentina y las respuestas sociales: las redes de clubes de Trueque", Revista Confluencia, 1, 115-158. Disponible en:

https://bdigital.uncuyo.edu.ar/objetos_digitales/211/Lacoste.Confluencia1.pdf

LAVILLE, J.L. (2004): "El marco conceptual de la economía solidaria". En: Laville, Jean Louis (comp.). Economía Social y Solidaria: una visión europea. Buenos Aires: Universidad General Sarmiento, Fundación OSDE y Editorial Altamira, 207-235.

LEMA, S., BAUZÁ, J. \& GORDILLO, L. (2005): "El movimiento de desocupados en Mendoza: logros, límites y potencialidades de las nuevas organizaciones", 7ํㅡㅁongreso Nacional de Estudios del Trabajo: Nuevos escenarios en el mundo del trabajo: rupturas y continuidades. Facultad de Ciencias Económicas, Universidad Nacional de Buenos Aires, agosto.

LEMAITRE, A. (2009): "Hacia una caracterización de la economía solidaria en Brasil”, Revista Venezolana de Economía Social, 17 (9). Disponible en:

https://www.redalyc.org/pdf/622/62213206002.pdf

MAUSS, M. (2012): Ensayo sobre el don. Formas y función del intercambio en las sociedades arcaicas. Buenos Aires: Katz editores.

MESA DE ECONOMÍA SOCIAL MENDOZA [MESM] (2009): Propuesta para la próxima reunión ampliada de la Mesa de Economía Social [Documento interno]. Mendoza, Argentina.

MONZÓN CAMPOS, J.L. \& CHAVES ÁVILA, R. (2012): La Economía Social en la Unión Europea. Comité Económico y Social Europeo, Bruselas. Disponible en:

http://hdl.handle.net/10550/39365.

MORA JIMÉNEZ, H. \& HINKELAMMERT, F. (2005): Hacia una economía para la vida (1a․ ed.), San José, Costa Rica: DEI. Colección Economía Teológica. 
ORTUBIA DÍAZ, E. \& JURADO, E. (2015): “Empresas Recuperadas por sus Trabajadores en Mendoza y las estrategias de distribución de sus productos". En: Mutuberría Lazarini, Valeria y Plotinsky, Daniel (comps.), La economía social y solidaria en la historia de América Latina y el Caribe: cooperativismo, desarrollo comunitario y estado (1 ra. Ed.). Ciudad Autónoma de Buenos Aires: IDELCOOP, 143-152.

PASTORE, R. (2010): “Un panorama del resurgimiento de la economía social y solidaria en Argentina", Revista de Ciencias Sociales, 18 (2). Universidad Nacional de Quilmes. Disponible en: http://www.unq.edu.ar/advf/documentos/59400be7cff6a.pdf

PÉREZ, R. (2009): Recuperando Mendoza. La historia de las empresas recuperadas de Mendoza contada por sus protagonistas. (1 $\mathrm{ra}$. Ed.). Mendoza: Espejo de mundos.

POLANYI, K. (2001): The Great Transformation: the Political and Economic Origins of Our Time. Boston: Beacon Press.

QUINN PATTON, M. (2002): “Two decades of developments in qualitative inquiry”, Qualitative Social Work, 1(3), 261-283. DOI: 10.1177/1473325002001003636

RAZETO, Luis (1993): Los caminos de la economía de solidaridad. Santiago de Chile: Ediciones Vivarium

ROITMAN, R. (Dir) (2011): Estudio de caracterización y cuantificación de la Economía Social Argentina. Primera Fase. Informe Final. Proyecto: Convenio Instituto Nacional de Asociativismo y Economía Social, y el Foro de Ciencias y Tecnología para la Producción.

RINCÓN GAMBA, L. (2012): “Territorios y sujetos de la economía social y solidaria”, Otra Economía, 10 (6), enero-junio, 24-36. DOI: 10.4013/otra.2012.610.03

ROFMAN, A. (2014): “La economía solidaria avanza decididamente”, Voces en el Fénix, Buenos Aires: Facultad Ciencias Económica, 37, 86-91. Disponible en: https://www.vocesenelfenix.com/sites/default/files/pdf/86_11fenix37\%20baja.pdf

SAJARDO, A. \& CHAVES, R. (1997): "El Tercer Sector como realidad institucional: Delimitación y cuantificación en España y otros 82 países desarrollados", Ekonomiaz: Revista vasca de economía, 39, 82-107. Disponible en: https://dialnet.unirioja.es/descarga/articulo/273740.pdf

SALOMONE, M. (2012): “Territorio y Política: Disputa Social y Memoria Histórica. La Defensa de la Estación del Ferrocarril como espacio público, Mendoza 2006-2008”, Cuadernos de la Facultad de Humanidades y Ciencias Sociales, Argentina, Jujuy: Universidad Nacional de Jujuy, 41, 145-175. Disponible en:

http://revista.fhycs.unju.edu.ar/revistacuadernos/index.php/cuadernos/article/view/31

SANTOS, M. (1996): A natureza do espaço. Técnica e Tempo. Razão e Emoção. São Paulo: Hucitec. 
SILVEIRA, M.L. (2013): "Tiempo y espacio en geografía: dilemas y reflexiones", Revista de Geografía Norte Grande, 54, 9-29. D0I: dx.doi.org/10.4067/S0718-34022013000100002.

SINGER, P. (2014): “La economía solidaria en Brasil”. En: La economía Populary Solidaria. El Ser Humano Sobre el Capital 2007-2013, Instituto de Economía Popular y Solidaria, Quito, 47-56.

STAKE, R. (1998): Investigación con estudio de casos. Madrid: Ediciones Morata.

SVAMPA, M. (2006): “La Argentina: Movimientos Sociales e Izquierdas”, Entre Voces. Revista del grupo Democracia y Desarrollo Local, 5, Quito.

TIRIBA, L. (2004): "0 trabalho no olho da rua fronteiras da economia popular e da economia informal", Revista Trabalho Necessário, 2(2). D0I: 10.22409/tn.2i2.p3650

VASILACHIS, I. (2006): "La investigación cualitativa”. En Vasilachis, I. (coord.), Estrategias de investigación cualitativa, Barcelona: Gedisa, 23-64.

VUOTTO, M. (2009): "Algunas referencias sobre la noción de trabajo asociado en el siglo XIX", Revista Economía, Venezuela: Universidad de los Andes, 28, 103-127. Disponible en: https:// www.redalyc.org/pdf/1956/195617795005.pdf.

ZIBECHI, R. (2006): “La emancipación como producción de vínculos”. En: Ceceña, Ana Esther (Ed.): Los desafíos de las emancipaciones en un contexto militarizado. Ciudad Autónoma de Buenos Aires: CLACSO, 123-149.

\section{Otros documentos}

ANTOLÍN, V. (2006). "20 de diciembre, acto y movilización de la Multisectorial de Mendoza. Se conformó la Mesa Promotora Intersectorial de Economía Social y Desarrollo Local en Mendoza". Mensaje dirigido a lista de correo electrónico. 19 de diciembre de 2006.

ASOCIACIÓN CIVIL FORMAR (s.f.). Recuperado el 7 de enero de 2017 de: http://www.formar.org.ar/bancopopulardelabuenafe/presentacion/

DIRECCIÓN DE ESTADÍSTICAS E INVESTIGACIONES ECONÓMICAS [DEIE] (s.f.). "Encuesta Permanente de Hogares Continua. Tasa de Desocupación de la población de 14 años y más según sexo, posición en el hogar y grupos de edad. Aglomerado Gran Mendoza. Tercer trimestre 2003 - Cuarto trimestre 2007”. Ministerio de Economía, Infraestructura y Energía, Gobierno de Mendoza. Recuperado el 12 de enero de 2017 de: http://www.deie.mendoza.gov.ar/tematicas/eph/archivos/Poblacion\%20desocupadoseph.xls.

FORO DE ECONOMÍA SOCIAL DE MENDOZA [FESM] (2009): Hacia una política provincial de economía social [Documento preliminar]. Mendoza. 
FORO DE ECONOMÍA SOCIAL DE MENDOZA [FESM] (2013). Documento de difusión inédito.

LEY PROVINCIAL № 8.435 (2012). “Creación del Programa de Promoción de la Economía Social y Solidaria", Mendoza, Argentina, 23 de julio de 2012. Recuperado el 3 de marzo de 2014 de: http://base.socioeco.org/docs/ley_economia_social_de_mendoza.pdf

MINISTERIO DE DESARROLLO SOCIAL. PRESIDENCIA DE LA NACIÓN (2012). "El microcrédito: confianza y apoyo para grandes transformaciones". 29 de mayo de 2012. Recuperado el 7 de enero de 2017 de: http://www.desarrollosocial.gob.ar/informes/el-microcredito-confianza-y-apoyo-para-grandes-transformaciones/

RUIZ, E. (2011). "La ley de Economía Social es una herramienta de incidencia política", 8300 web, Cooperativa de Trabajo para la Comunicación. 18 de noviembre de 2011. Recuperado el 10 de diciembre de 2016 de: http://www.8300.com.ar/2011/11/18/la-ley-de-economia-social-es-una-herramienta-de-incidencia-politica/

TITIRO, M. (2003). "Piqueteros: de la protesta al trabajo comunitario en una finca", Diario Los Andes. 25 de agosto de 2003. Recuperado el 6 de abril de 2015 de:

http://www.losandes.com.ar/notas/2003/8/25/economia-82772.asp.

\section{Entrevistas y notas de campo}

Antonio (1 de agosto de 2015). Entrevista de Emanuel Jurado [Audio disponible en mp3]. Referente de organización distribuidora de productos de la ESS y del Foro de Economía Social de Mendoza, Ciudad de Mendoza.

Diego (3 de diciembre de 2015). Entrevista de Emanuel Jurado [Audio disponible en mp3]. Referente de microcrédito por parte del estado y del Foro de Economía Social de Mendoza, Ciudad de Mendoza.

Ernesto (26 de julio de 2015). Entrevista de Emanuel Jurado [Audio disponible en mp3]. Referente de los Clubes de Trueque y de la Mesa de Economía Social Mendoza, Ciudad de Mendoza.

Hugo (1 de agosto de 2015). Entrevista de Emanuel Jurado [Audio disponible en mp3]. Referente de la Universidad Nacional de Cuyo en tema de ESS y del Foro de Economía Social de Mendoza, Ciudad de Mendoza.

Notas de campo, 10 de mayo de 2012. 5 Foro Regional de Economía Social, Ciudad de Mendoza.

Notas de campo, 6 de noviembre de 2010. 2ํForo Regional de Economía Social "Las Heras", Departamento de Las Heras. 